\section{SOI: $1.1 /$ TAS DOI: $10.15863 / \mathrm{TAS}$ International Scientific Journal Theoretical \& Applied Science}

Shehryar Noor
Dr., consultant general surgeon in Khyber Teaching Hospital Peshawar, Pakistan. shehryar.md@gmail.com

p-ISSN: 2308-4944 (print) e-ISSN: 2409-0085 (online)

Year: $2018 \quad$ Issue: 09 Volume: 65

Published: $24.09 .2018 \quad$ http://T-Science.org
Nimra Iftikhar

Dr., WMO at govt Rural Dispensary Tarkhanawala,

Pakistan

nimraiftikhar200@gmail.com

Ali Sabahat

Dr., WMO at PKLI Mandibahauddin, Pakistan

s2_soulofswan@yahoo.com

\title{
MORBIDITY AND MORTALITY ASSOCIATED WITH SPONTANEOUS BACTERIAL PEROTONITIS
}

\begin{abstract}
Objective: To find out consequences of spontaneous bacterial peritonitis and its causative organisms and to determine sensitivity of these organisms for antibiotics.

Design and Duration: This is an observational descriptive study completed in duration of 8 months from October 2017 to May 2018.

Setting: This study was conducted in Khyber teaching Hospital Peshawar Pakistan.

Patients and Methods: All The cases presented in emergency ward of the hospital with spontaneous bacterial peritonitis with ascites due to liver cirrhosis, during the study period were selected for study. An inclusion criterion was developed for selecting patients for the study according to that patients with SBP directly presented to the hospital first time for this disease, having no other infective disease other than, having ascites due to liver cirrhosis only, No other cause of ascites, no history of trauma or invasive abdominal procedure leading to peritonitis. Patients from both male and female populations were included in this study. Under aseptic measures ascetic tap done using $10 \mathrm{ml}$ syringe and ascitic fluid sent for examination and culture sensitivity determined for isolated organisms. All cases in study group were admitted in the surgical ward and empirical management was given before culture report came. After culture report antibiotic was given accordingly. Written consent was taken from all study cases and also from the medical superintendant of the hospital. Data was analyzed in SPSS and Microsoft office version 2018.

Results: There were total 90 cases in this study having ascites due to liver cirrhosis and signs and symptoms of peritonitis. Age range of these cases was 32-74 years with mean age of $48 \pm 15.5$ years. Most of the cases were having age above 45 years. There were $55.6 \%$ male and $44.4 \%$ female cases. Ascitic fluid culture was positive in $47.8 \%$ and negative in $52.2 \%$ cases. Out of total cases with positive culture growth $55.8 \%$ showed gram negative bacteria, $30.2 \%$ gram positive and in $14 \%$ cases other organisms were isolated. In 43 culture positive cases $39.5 \%$ showed E.coli, 25.6\% streptococcus pneumonia, In 11.6\% Klebsiella, in 9.3\% staphylococcus aureus and in 13.9\% cases other organisms were isolated. Confidence level was $95 \%$ with P-value less than 0.05 .

Conclusion: Gram negative organisms are most common cause of spontaneous bacterial peritonitis in liver cirrhotic patients. E-coli is most common gram negative bacteria responsible for it. It is associated with high morbidity and mortality rate.

Key words: Spontaneous bacterial peritonitis, Liver cirrhosis, Ascitic fluid examination.

Language: English

Citation: Noor S, Iftikhar N, Sabahat A (2018) MORBIDITY AND MORTALITY ASSOCIATED WITH SPONTANEOUS BACTERIAL PEROTONITIS. ISJ Theoretical \& Applied Science, 09 (65): 149-153.

Soi: http://s-o-i.org/1.1/TAS-09-65-24 Doi: crossef https://dx.doi.org/10.15863/TAS.2018.09.65.24
\end{abstract}

\section{INTRODUCTION}

Viral Hepatitis is very common in Pakistan causing chronic liver disease and decompensated liver failure and liver cirrhosis. HCV is very common cause of liver cirrhosis. ${ }^{1}$ Cirrhosis of liver leads to portal hypertension causing vericeal bleeding, ascites and splenomegly. Ascites often develop to peritonitis due to infection of ascetic fluid. This is a complication of ascites leading to high morbidity and mortality rate. According to a study $\mathrm{HCV}$ prevalence in Pakistan is $4-12.5 \%$. Diagnostic criteria includes TLC more than 500/mm3, PMN above $250 / \mathrm{mm} 3$. In initial stages of spontaneous bacterial peritonitis no signs and symptoms develop and it is better to manage this condition before it becomes symptomatic. Its causative factors are Gram positive and gram negative organisms. ${ }^{2}$ Gram negative bacteria especially E coli is most commonly found in 
ascetic fluid culture. Other bacteria involved are Klebsiella, Streptococcus and staphylococcus. Culture and sensitivity of ascetic fluid was done. E Coli was Sensitive for ceftriaxone, cefotaxime, ciprofloxacin, levofloxacin and amikacin. Similarly most of the isolated bacteria showed sensitivity for ceftriaxone, cefotaxime, levofloxacin and ciprofloxacin and amikacin. Ceftazidim was found resistant by most of the causative bacteria. With the passage of time and use of antibiotics for minor daily infections develops resistant to antibiotics. ${ }^{3}$ All The cases presented in emergency ward of the hospital with spontaneous bacterial peritonitis with ascites due to liver cirrhosis, during the study period were selected for study. An inclusion criterion was developed for selecting patients for the study according to that patients with SBP directly presented to the hospital first time for this disease, having no other infective disease other than, having ascites due to liver cirrhosis only, No other cause of ascites, no history of trauma or invasive abdominal procedure leading to peritonitis. Patients from both male and female populations were included in this study. Use of high potency antibiotics and incomplete dosage makes patient resistant to antibiotics. Gram positive and anerobes were found were rarely causing peritonitis. Peritonitis due to intra abdominal abscess is most commonly caused by anerobes. In this study only those cases were included having ascites due to CLD and no intra abdominal abscess.

\section{Patients and Methods:}

This is a descriptive study of observational type carried out in Khyber teaching hospital Peshawar during the period of 7 months. All The cases presented in emergency ward of the hospital with spontaneous bacterial peritonitis with ascites due to liver cirrhosis, during the study period were selected for study. Viral Hepatitis is very common in Pakistan causing chronic liver disease and decompensated liver failure and liver cirrhosis. $\mathrm{HCV}$ is very common cause of liver cirrhosis. Cirrhosis of liver leads to portal hypertension causing vericeal bleeding, ascites and splenomegly. An inclusion criterion was developed for selecting patients for the study according to that patients with SBP directly presented to the hospital first time for this disease, having no other infective disease other than, having ascites due to liver cirrhosis only, No other cause of ascites, no history of trauma or invasive abdominal procedure leading to peritonitis. Patients from both male and female populations were included in this study. Under aseptic measures ascetic tap done using
$10 \mathrm{ml}$ syringe and ascitic fluid sent for examination and culture sensitivity determined for isolated organisms. All cases in study group were admitted in the surgical ward and empirical management was given before culture report came. After culture report antibiotic was given accordingly. Written consent was taken from all study cases and also from the medical superintendant of the hospital. Data was analyzed in SPSS and Microsoft office version 2018. Diagnostic criteria includes TLC more than $500 / \mathrm{mm} 3, \mathrm{PMN}$ above $250 / \mathrm{mm} 3$. In initial stages of spontaneous bacterial peritonitis no signs and symptoms develop and it is better to manage this condition before it becomes symptomatic. Its causative factors are Gram positive and gram negative organisms. Gram negative bacteria especially $\mathrm{E}$ coli is most commonly found in ascetic fluid culture. Patients with ascites and suspected case of spontaneous bacterial peritonitis were selected. Patients taking antibiotic therapy and ascites due to other disease were not included in this study.

\section{Results}

In this study 90 cases were included having ascites due to liver cirrhosis and those having signs and symptoms of peritonitis. Age range of these cases was 32-74 years with mean age of $48 \pm 15.5$ years. There were $9(10 \%)$ cases between age $30-40$ years, 39(43.3\%) between 41-50 years, 32(35.6\%) between 51-60 years, $6(6.7 \%)$ between $61-70$ years and $4(4.4 \%)$ above 70 years. Most of the cases were having age above 45 years. There were $50(55.6 \%)$ male and $40(44.4 \%)$ female cases. Ascitic fluid culture was positive in $43(47.8 \%)$ and negative in $47(52.2 \%)$ cases. Out of total cases with positive culture growth $24(55.8 \%)$ showed gram negative bacteria, $13(30.2 \%)$ gram positive and in $6(14 \%)$ cases other organisms were isolated. In 43 culture positive cases $17(39.5 \%)$ showed E.coli, $11(25.6 \%)$ streptococcus pneumonia, In $5(11.6 \%)$ Klebsiella, in $4(9.3 \%)$ staphylococcus aureus and in 6(13.9\%) cases other organisms were isolated. Confidence level was $95 \%$ with P-value less than 0.05. Data was analyzed in SPSS and Microsoft office version 2018. Diagnostic criteria includes TLC more than $500 / \mathrm{mm} 3, \mathrm{PMN}$ above $250 / \mathrm{mm} 3$. In initial stages of spontaneous bacterial peritonitis no signs and symptoms develop and it is better to manage this condition before it becomes symptomatic. Its causative factors are Gram positive and gram negative organisms. Gram negative bacteria especially $\mathrm{E}$ coli is most commonly found in ascetic fluid culture. 


\begin{tabular}{l|lr|ll|ll} 
& ISRA (India) & $=\mathbf{1 . 3 4 4}$ & SIS (USA) & $=\mathbf{0 . 9 1 2}$ & ICV (Poland) & $=\mathbf{6 . 6 3 0}$ \\
Impact Factor: & ISI (Dubai, UAE) $=\mathbf{0 . 8 2 9}$ & PUHL (Russia) $=\mathbf{0 . 1 5 6}$ & PIF (India) & $=\mathbf{1 . 9 4 0}$ \\
& GIF (Australia) & $=\mathbf{0 . 5 6 4}$ & ESJI (KZ) & $=\mathbf{4 . 1 0 2}$ & IBI (India) & $=\mathbf{4 . 2 6 0}$ \\
& JIF & $=1.500$ & SJIF (Morocco) & $=\mathbf{2 . 0 3 1}$ & & \\
\hline
\end{tabular}

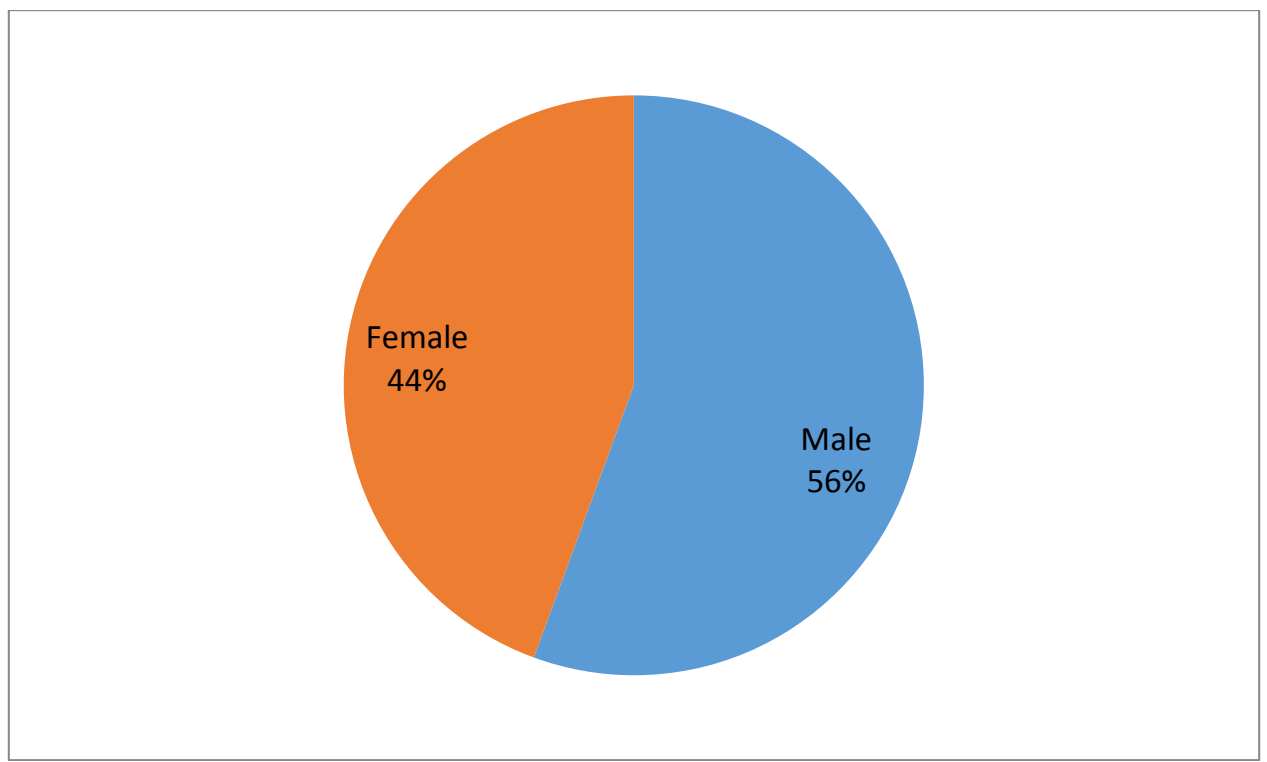

Figure-1 Gender distribution of patients in study group $(n=90)$

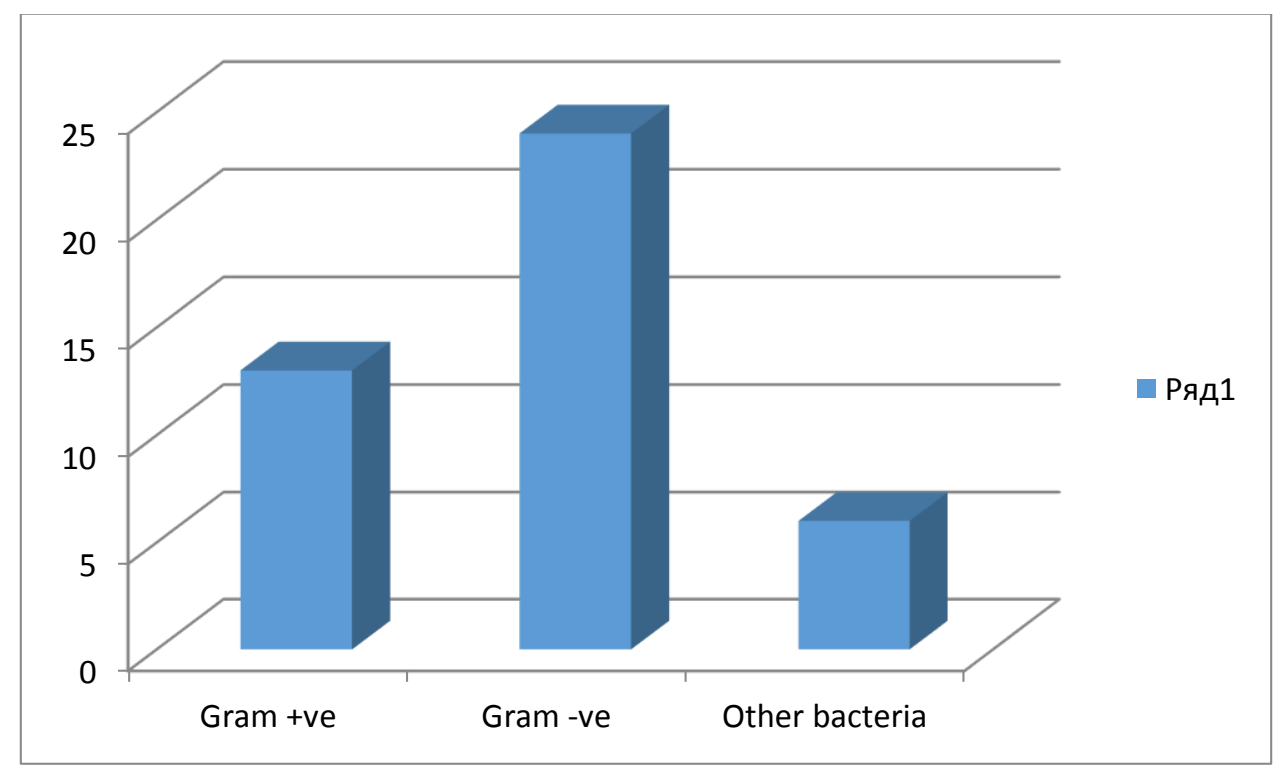

Figure-2 Frequency of gram positive and negative bacteria among culture positive cases 


\begin{tabular}{|c|c|c|c|c|c|c|}
\hline Impact Factor: & $\begin{array}{l}\text { ISRA (India) } \\
\text { ISI (Dubai, UAE } \\
\text { GIF (Australia) } \\
\text { JIF }\end{array}$ & $\begin{array}{r}=1.344 \\
=0.829 \\
=0.564 \\
=1.500\end{array}$ & $\begin{array}{l}\text { SIS (USA) } \\
\text { PИHЦ (Russia) } \\
\text { ESJI (KZ) } \\
\text { SJIF (Morocco) }\end{array}$ & $\begin{array}{l}=0.912 \\
=0.156 \\
=4.102 \\
=2.031\end{array}$ & $\begin{array}{l}\text { ICV (Poland) } \\
\text { PIF (India) } \\
\text { IBI (India) }\end{array}$ & $\begin{array}{l}=6.630 \\
=1.940 \\
=4.260\end{array}$ \\
\hline
\end{tabular}

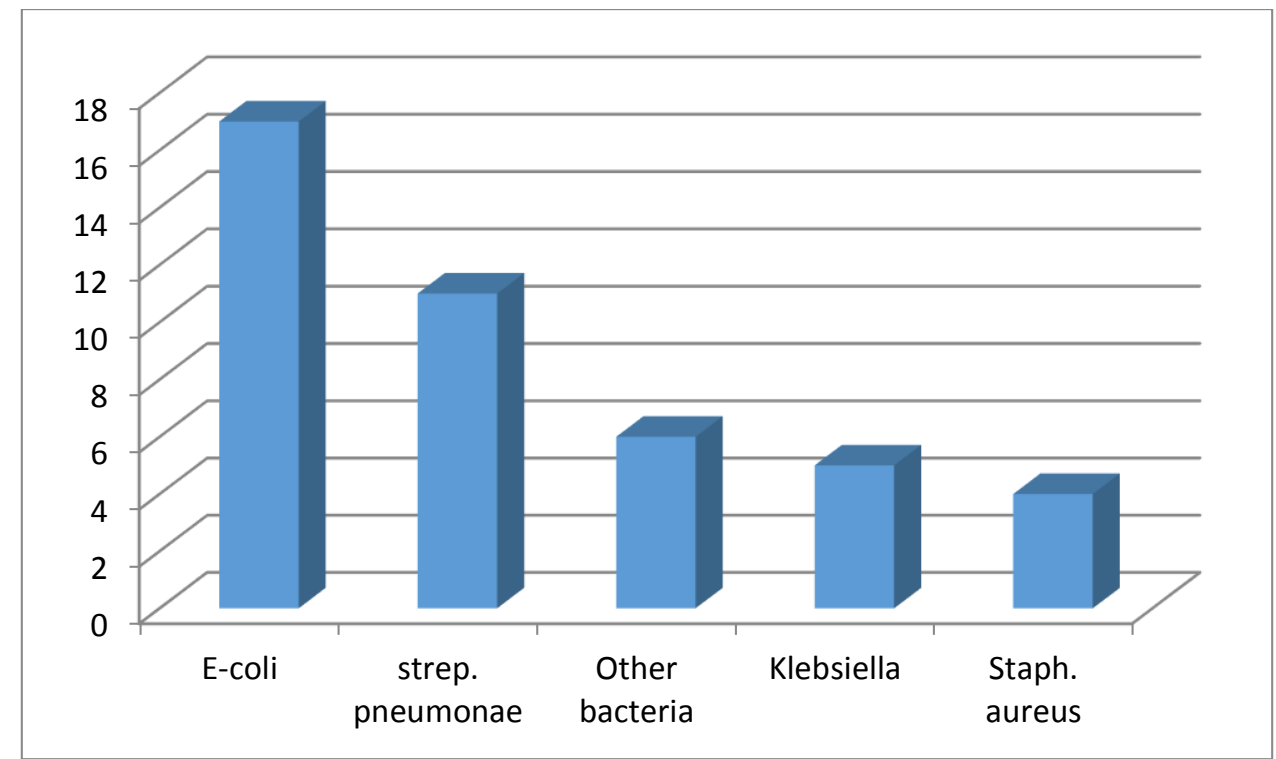

Figure-3 Frequency of organisms found on ascitic fluid culture $(n=43)$

Age distribution of cases among study group

Table-1

\begin{tabular}{|c|c|c|}
\hline Ages of patients (years) & Number of Patients (n) & \% \\
\hline $30-40$ & 9 & 10 \\
\hline $41-50$ & 39 & 43.3 \\
\hline $51-60$ & 32 & 35.6 \\
\hline $61-70$ & 6 & 6.7 \\
\hline Above 70 & 4 & 4.4 \\
\hline Total & $\mathbf{9 0}$ & $\mathbf{1 0 0}$ \\
\hline
\end{tabular}

\section{DISCUSSION}

Patients with liver cirrhosis develop ascites due to decreased oncotic pressure of blood and intravascular fluid comes out of vessels into peritoneal cavity. ${ }^{4}$ This is due to decreased synthesis of major blood protein albumin due to liver failure. Ascitic fluid can be infected with bacteria and leads to spontaneous bacterial peritonitis which often occurs in the patients of CLD with ascites. There are many other causes of ascites like heart failure, intra abdominal malignancy, peritoneal malignancy, Ovarian cancer etc. This type of peritonitis is managed by giving intravascular fluids and good antibiotic determined on cuture and sensitivity of ascetic fluid. ${ }^{5}$ Ascitic tab is done and fluid is sent for culture sensitivity and most sensitive antibiotic is used as treatment. Viral Hepatitis is very common in Pakistan causing chronic liver disease and decompensated liver failure and liver cirrhosis. HCV is very common cause of liver cirrhosis. Cirrhosis of liver leads to portal hypertension causing vericeal bleeding, ascites and splenomegly. Ascites often develop to peritonitis due to infection of ascetic fluid. ${ }^{6}$ This is a complication of ascites leading to high morbidity and mortality rate. According to a study HCV prevalence in Pakistan is $4-12.5 \%$. Diagnostic criteria includes TLC more than $500 / \mathrm{mm} 3, \mathrm{PMN}$ above $250 / \mathrm{mm} 3$. In initial stages of spontaneous bacterial peritonitis no signs and symptoms develop and it is better to manage this condition before it becomes symptomatic. Its causative factors are Gram positive and gram negative organisms. ${ }^{7}$ Gram negative bacteria especially $\mathrm{E}$ coli is most commonly found in ascetic fluid culture. Ascitic fluid culture was positive in $43(47.8 \%)$ and negative in $47(52.2 \%)$ cases. Out of total cases with positive culture growth $24(55.8 \%)$ showed gram negative bacteria, $13(30.2 \%)$ gram positive and in $6(14 \%)$ cases other organisms were isolated. In 43 culture positive cases $17(39.5 \%)$ showed E.coli, 11(25.6\%) streptococcus pneumonia, In $5(11.6 \%)$ Klebsiella, in $4(9.3 \%)$ staphylococcus 
aureus and in $6(13.9 \%)$ cases other organisms were isolated. Confidence level was $95 \%$ with P-value less than 0.05. Data was analyzed in SPSS and Microsoft office version 2018. Diagnostic criteria includes TLC more than 500/mm3, PMN above $250 / \mathrm{mm} 3$. In initial stages of spontaneous bacterial peritonitis no signs and symptoms develop and it is better to manage this condition before it becomes symptomatic. ${ }^{8}$ This is a descriptive study of observational type carried out in Khyber teaching hospital Peshawar during the period of 7 months. All The cases presented in emergency ward of the hospital with spontaneous bacterial peritonitis with ascites due to liver cirrhosis, during the study period were selected for study. Viral Hepatitis is very common in Pakistan causing chronic liver disease and decompensated liver failure and liver cirrhosis. HCV is very common cause of liver cirrhosis. . Its causative factors are Gram positive and gram negative organisms. ${ }^{9}$ Gram negative bacteria especially E coli is most commonly found in ascetic fluid culture. Patients with ascites and suspected case of spontaneous bacterial peritonitis were selected. Patients taking antibiotic therapy and ascites due to other disease were not included in this study. ${ }^{10}$ Many studies have been done in Asian countries on this disease but still more work is required in this aspect. Public awareness about transmission of disease can reduce its incidence.

\section{Conclusion}

Ascites occurs in patients with liver cirrhosis. Bacterial infection of ascitic fluid leads to peritonitis. Gram negative organisms are most common cause of spontaneous bacterial peritonitis in liver cirrhotic patients. Among Gram negative bacteria E-coli is mostly responsible for peritonitis in liver cirrhotic patients. It is associated with high morbidity and mortality rate. Proper antibiotic treatment after culture and sensitivity is a treatment of choice.

\section{References:}

1. Sheer AT, Runyon AB. (2005) Spontaneous bacterial peritonitis. Digestive diseases 2005; 23:39-46.

2. Nadeem MA, Waseem T, Sheikh AM, Grumman N, Irfan K, Hasnain SS. (2004) Hepatitis $\mathrm{C}$ virus: an alarmingly increasing cause of liver cirrhosis in Pakistan Pak J Gastroenterol 2004; 23:45-46.

3. Hashim R, Hussain AB, Rehman K. (2005) Seroprevalence of Hepatitis-C virus antibodies among healthy young men in Pakistan. Pak J Med Res 2005;44:140-142.

4. Khan MD, Shaikh RA, Ashfaq M, Waheed I, Bhatti T, Ahmad S. (2004) Frequency of asymptomatic spontaneous bacterial peritonitis in chronic liver disease patients with presentation of ascites. Ann KE Med Coll 2004; 10:144-145.

5. Runyon BA, Canawati HN, Akriviadis EA. (1988) Optimization of ascitic fluid culture technique. Gastroenterology 1988; 95:1351.
6. Cholonqitas E, Paptheochoridis GV, Lahanas A, Xanthnki A, Kontou- Kastellanous, Archimandritis AJ. (2005) Increasing frequency of Gram-positive bacteria in spontaneous bacterial peritonitis. Liver Int 2005; 25:57-61.

7. Fernandez J, Navasa M, Gomez J. (2002) Bacterial infections in cirrhosis: Epidemiological changes with invasive procedures and norfloxacin prophylaxis. Hepatology 2002; 35:140.

8. Park YH, Lee HC, Song HG, Jung S, Ryu SH, Shin JW. (2003) Recent increase in antibiotic resistant microorganism in patient with spontaneous bacterial peritonitis adversely affects the clinical outcome in Korea. J Gastroentrol Hepatol.2003; 18:927-933.

9. Such J, Runyon BA. (1998) Spontaneous bacterial peritonitis. Clinical infectious diseases. 1998 Oct 1:669-74.

10. Guarner C, Soriano G. (1997) Spontaneous bacterial peritonitis. InSeminars in liver disease 1997 (Vol. 17, No. 03, pp. 203-217). 